\title{
Análise da resposta patológica do câncer de mama em pacientes submetidas a terapia neoadjuvante em uma clínica privada de Cascavel/PR
}

\author{
Pathological response analysis of breast cancer in patients submitted to neoadjuvant therapy in a \\ private clinic of Cascavel/PR \\ Análisis de la respuesta patológica del cáncer de mama en pacientes sometidos a terapia \\ neoadyuvante en una clínica privada de Cascavel/PR
}

Recebido: 26/04/2021 | Revisado: 03/05/2021 | Aceito: 10/05/2021 | Publicado: 27/05/2021

Isabel Cristina Ranzan

ORCID: https://orcid.org/0000-0002-4940-8184 Centro Universitário da Fundação Assis Gurgacz, Brasil E-mail: isabelranzan@ hotmail.com

Ayrton Pereira de Aguiar Neto

ORCID: https://orcid.org/0000-0002-5746-0687

Universidade Cesumar (UniCesumar), Brasil

E-mail: ayrtonaguiarneto@hotmail.com

Rubens Furlan Neto

ORCID: https://orcid.org/0000-0001-6295-7201

Centro Universitário da Fundação Assis Gurgacz, Brasil

E-mail: rubensfurlanneto@gmail.com

Rodolfo Ardengue Rosolen Tessaro

ORCID: https://orcid.org/0000-0001-7428-3566

Centro Universitário da Fundação Assis Gurgacz, Brasil E-mail: rodolfoartessaro@gmail.com

Priscila Pesseti Falconi

ORCID: https://orcid.org/0000-0002-1814-1034

Centro Universitário da Fundação Assis Gurgacz, Brasil

E-mail: pripfalconi@gmail.com

Gabriela Sacuno Bonilha

ORCID: https://orcid.org/0000-0002-1689-6126

Centro Universitário da Fundação Assis Gurgacz, Brasil

E-mail: gabrielasacuno@hotmail.com

Karla Mulinari Vicini

ORCID: https://orcid.org/0000-0001-6864-8565

Centro Universitário da Fundação Assis Gurgacz, Brasil

E-mail: kaarla.vicini@ hotmail.com

Gabriel Orige Rauen

ORCID: https://orcid.org/0000-0002-8663-4279

Centro Universitário da Fundação Assis Gurgacz, Brasil

E-mail: gabrauen@ hotmail.com

Douglas Soltau Gomes

ORCID: https://orcid.org/0000-0002-8929-2024

Centro Universitário da Fundação Assis Gurgacz, Brasil

E-mail: drdouglasgomes@gmail.com

\begin{abstract}
Resumo
O objetivo do presente trabalho foi analisar o perfil clínico-patológico das pacientes diagnosticadas com câncer de mama e submetidas ao tratamento com quimioterapia neoadjuvante no Centro de Oncologia do Oeste do Paraná COOP no período de julho de 2014 a julho de 2019. As terapias neoadjuvantes são realizadas com o objetivo de reduzir a carga tumoral e melhorar a resposta patológica completa (pCR) em pacientes com tumores avançados e conservar a mama em tumores iniciais. A resposta patológica é uma forma de avaliar a efetividade dessa modalidade de tratamento, bem como os benefícios trazidos por ela. O estudo em questão fez uma análise quantitativa, qualitativa e descritiva, de forma retrógrada, utilizando prontuários físicos do COOP. Conclui-se que há associação estatística de pacientes que alcançaram a pCR com pacientes mais jovens que apresentam maiores níveis de Ki-67, ausência de receptores hormonais de estrogênio e progesterona e presença de receptores HER-2. Deve-se, portanto, considerar essa modalidade de tratamento em pacientes com perfil semelhante a fim de obter melhor desfecho clínico.
\end{abstract}

Palavras-chave: Neoplasias da mama; Resposta patológica; Quimioterapia neoadjuvante. 


\begin{abstract}
The present study aimed to analyze the clinical-pathological profile of patients diagnosed with breast cancer and treated with neoadjuvant chemotherapy at COOP from July 2014 to July 2019. Neoadjuvant therapies have the purpose of reduce the tumor burden and improving the pathological complete response (pCR) in patients with advanced tumors and conserving the breast in initial tumors. The pathological response is a way to evaluate the effectiveness of this modality of treatment, as well as the benefits brought by it. The study in question made a quantitative, qualitative and descriptive analysis, in a retrograde way, using physical records from COOP. The conclusion is that there is a statistical association of patients who achieved pCR with younger age, higher levels of Ki67, absense of estrogen and progesterone hormonal receptor and presence of HER-2 receptor. Therefore, this treatment modality should be considered in patients with a similar profile to obtain a better clinical outcome.
\end{abstract}

Keywords: Breast neoplasms; Pathological response; Neoadjuvant chemotherapy.

\title{
Resumen
}

El objetivo de este estudio fue analizar el perfil clínico-patológico de pacientes diagnosticadas con cáncer de mama y en tratamiento con quimioterapia neoadyuvante en el Centro de Oncología del Oeste de Paraná (COOP) desde julio de 2014 a julio de 2019. Terapias neoadyuvantes se realizan con el objetivo de reducir la carga tumoral y mejorar la respuesta patológica completa (pCR) en pacientes con tumores avanzados y conservando la mama en los tumores iniciales. La respuesta patológica es una forma de evaluar la efectividad de esta modalidad de tratamiento, así como los beneficios que aporta. El estudio en cuestión realizó análisis cuantitativo, cualitativo y descriptivo de forma retrógrada, utilizando registros físicos de COOP. Concluimos que existe una asociación estadística de pacientes que alcanzaron pCR con pacientes más jóvenes que tienen niveles más altos de Ki-67, ausencia de receptores hormonales de estrógeno y progesterona y presencia de receptores HER-2. Por tanto, esta modalidad de tratamiento debe ser considerado en pacientes con perfil similar para obtener mejor resultado clínico.

Palabras clave: Neoplasias de la mama; Respuesta patológica; Quimioterapia neoadyuvante.

\section{Introdução}

A quimioterapia neoadjuvante (NACT) é uma linha de tratamento que vem sendo cada vez mais difundida para o câncer de mama. Um dos seus objetivos, principalmente em tumores grandes em que a cirurgia é impossibilitada, é a diminuição do tamanho do tumor, facilitando assim a sua ressecção cirúrgica (Asselain et al, 2018).

Estatisticamente a NACT tem sido correlacionada à diminuição de mastectomias radicais e ao aumento da conservação de mamas comparadas a terapia adjuvante de acordo com trabalho realizado pelo Early Breast Cancer Trialists' Collaborative Group (EBCTCG) em uma análise de ensaios clínicos randomizados, em 2018. Segundo o estudo, foi possível concluir que o uso da NACT teve um maior efeito em pacientes cujo o tumor era classificado como grande (20-49 mm ou > $50 \mathrm{~mm})$, diminuindo a escala da cirurgia, diferentemente do observado em tumores cujo o tamanho era pequeno (<20 mm), não tendo um efeito tão pronunciado (Asselain et al, 2018). Este fato também foi exposto em revisão feita a partir de dados apresentados na National Cancer Institute State of the Science Conference on Preoperative Therapy in Invasive Breast Cancer em que constatou-se que a NACT melhora as taxas de conservação da mama (Gralow et al., 2008); e concluído em trabalho realizado de 2013 a 2015 com 534 pacientes que expuseram a NACT como fator promissor na redução de estágios da axila de pacientes que possuíam linfonodos positivos (particularmente nos subtipos de tumor HER2+ e triplo-negativo) evitando assim a dissecção de linfonodos axilares em 48\% dos pacientes analisados (Mamtami et al., 2016).

A resposta patológica completa (pCR) é um sistema de estadiamento patológico que foi desenvolvido para a estratificação de risco após a realização de quimioterapia neoadjuvante e vem sendo utilizada como um bom marcador da eficácia do tratamento para o câncer de mama (Von Minckwitz et al., 2012; Osório et al, 2012). Atualmente é o sistema mais utilizado e definido pela ausência de câncer invasivo em tecido mamário ou linfonodal após a conclusão da quimioterapia neoadjuvante (Campbell et al., 2017).

De acordo com resposta à quimioterapia neoadjuvante, já foi comprovado que pacientes que não possuem resíduos invasivos in situ na mama têm uma taxa de sobrevida maior do que os pacientes que possuem carcinoma ductal residual in situ (Von Minckwitz et al., 2012). Sendo assim, atualmente a pCR é um forte fator prognóstico de recorrência em pacientes com câncer invasivo residual de mama (Huang et al., 2004; Mcguire et al.,2007), sendo associado com melhora da sobrevida se 
alcançado pCR na mama e em linfonodos regionais após NACT (Fayanju et al., 2018). Resultado comprovado em um trabalho prospectivo que analisou um banco de dados de 439 pacientes que receberam terapia neoadjuvante no Royal Marsden Hospital de Londres, de 2006, que ficou constatado uma sobrevida livre de doença em 5 anos de $80 \%$ em pacientes com pCR, comparado a $61 \%$ de sobrevida livre de doença em pacientes que possuem carcinoma ductal residual in situ - resposta patológica parcial (Jones et al., 2006). A análise combinada de estudos com a terapia neoadjuvante de câncer de mama do The Collaborative Trials in Neoadjuvant Breast Cancer com 11.955 pacientes também caracterizou uma relação de melhora na sobrevida livre da doença (SLD), assim como na sobrevida global (SG) se obtido pCR em mama e axila, comparada à obtenção apenas da pCR em mama. E a American Joint Committee on Cancer mostrou que quando alcançada pCR o risco de morte foi reduzido (Cortazar, 2014; Cortazar et al., 2015). No Protocolo B-18 do National Surgical Adjuvant Breast and Bowel Project (NSABP) a taxa de SLD e SG foram de 75\% e 85\%, respectivamente, em acompanhamento médio de 9 anos dos pacientes que tiveram um PCR, em comparação com 58\% e 73\% para pacientes com doença residual (Wolmark et al., 2001). Resultado similar apontado pelo Protocolo NSABP B-27 (Rastogi et al., 2008).

O presente estudo teve como objetivo principal a avaliação de pacientes que apresentaram pCR após terem feito a utilização de quimioterapia neoadjuvante. Tal comparação surge da importância que foi estabelecida através de grandes ensaios clínicos, como os descritos acima, a respeito da quimioterapia neoadjuvante resultando em uma maior de SLD e SG dentre os pacientes que alcançaram a pCR, comparado aquelas que obtiveram uma resposta parcial ao tratamento.

Diante dessa realidade, esse estudo traz a análise da porcentagem de pacientes que obtiveram resposta patológica completa, feita por meio da comparação do perfil anatomopatológico dos tumores pré e pós realização de quimioterapia neoadjuvante, além do perfil clínico das pacientes.

\section{Metodologia}

Trata-se de um estudo observacional, transversal, retrospectivo e de caráter quantitativo conduzido no Centro de Oncologia do Oeste do Paraná - COOP, por meio da revisão de prontuários médicos de pacientes submetidas ao tratamento do câncer de mama com quimioterapia neoadjuvante. Como base metodológica foi utilizado o trabalho de Pereira et al (2018).

Foram selecionados os casos de mulheres diagnosticadas com câncer de mama que realizaram o tratamento com quimioterapia neoadjuvante no período compreendido entre julho de 2014 até julho de 2019 no COOP. Foram excluídos da amostra pacientes do sexo masculino, pacientes que não realizaram o tratamento com quimioterapia e pacientes em que os dados coletados estavam insuficientes, resultando assim em 29 prontuários analisados. A coleta dos dados foi realizada através de questionário no período de setembro de 2020 a novembro de 2020.

Após a coleta, os dados foram tabulados e analisados no programa Epi info e RStudio. As seguintes variáveis foram avaliadas: idade média, estadiamento clínico, utilizando o aplicativo Breast Cancer Staging TNM 8, licenciado pela American Joint Comitee on Cancer (AJCC), perfil anatomopatológico: tipo histológico, perfil hormonal (RH, HER-2 ou KI-67), subtipo molecular (Luminal A, Luminal B, HER-2 ou Triplo Negativo), tamanho da lesão pré-quimioterapia na ressonância magnética, presença de doença no anatomopatológico após realização da quimioterapia neoadjuvante.

Os testes estatísticos de associação foram realizados no software RStudio na versão 1.4.1103. Para o cálculo do valor de p referente as diferenças de prevalências entre grupos, foi utilizado o teste de Fisher. Na comparação de médias entre grupos foram utilizados o teste de Mann-Whitney. As tabelas descritivas foram construídas utilizando software Microsoft Excel e Word.

O projeto de pesquisa foi submetido ao Comitê de Ética em Pesquisa com Seres Humanos do Centro Universitário FAG e aprovado pelo CAAE ( $\mathrm{n}^{\circ}$. 32180620.1.0000.5219). 


\section{Resultados e Discussão}

A Tabela 1 descreve dados dos participantes da pesquisa. A maioria apresenta idade entre 31 e 50 anos (69\%), com estadiamento TNM I e II (52\%), presença de receptor de estrogênio (79\%) e de progesterona (76\%) e Ki-67 positivo (59\%).

Dentre as 29 mulheres selecionadas o índice de remissão completa da doença foi alcançado em um total de 13 pessoas (44,82\%), taxa que se apresentou maior do que comparado em demais pesquisas analisadas (Fayanju et al., 2018; Andrade et al., 2013; TAN et al., 2009). Em um estudo de coorte retrospectivo realizado no Brasil de pacientes com o diagnóstico de câncer de mama localmente avançado, foram analisadas ao todo 298 pessoas, chegando a uma taxa de $17,1 \%$ de PCR de tumor primário e de linfonodos acometidos (Andrade et al., 2013). Resultado este que é semelhante a pesquisa realizada com 20.000 pacientes com câncer de mama da National Cancer Data Base dos Estados Unidos (NCDB), em que foi possível identificar uma PCR de mama e linfonodos axilares em 19,2\% (n=6.370) dos pacientes, os quais possuíam estágios clínicos que variavam de 1 a 3 (Fayanju et al., 2018). Acredita-se que a maior taxa alcançada no presente estudo se deve ao fato do número menor de pacientes que se enquadram na pesquisa, assim como uma maior taxa de pacientes que apresentavam um perfil de biomarcadores histológicos HER-2 positivos de 41\%. Tal marcador se mostrou em nosso estudo, de acordo com a Tabela 2 $(\mathrm{p}<0,001)$ como um preditor positivo para se alcançar a PCR, acordando com demais estudos (Esserman et al., 2012; Fayanju et al., 2018).

Além das terapias tradicionais utilizando quimioterapia, novas modalidades terapêuticas utilizando anticorpos estão ampliando o arsenal de tratamentos que médicos dispõe para tratamento do câncer. Em estudo realizado por Llombard-Cussac et al (2017) pacientes com câncer de mama HER2 positivo também apresentaram maior evolução para resposta patológica completa $(\mathrm{p}=0,0004)$ com a utilização de traustuzumab e lapatinib visando bloqueio duplo do receptor HER2. Metanálise conduzida por Wang et al (2020) mostrou superioridade do bloqueio duplo em pacientes com HER2 positivo na comparação com bloqueio com uma única droga. Além disso, a associação do anticorpo monoclonal transtuzumab associado a quimioterapia neoadjuvante aumentou a prevalência de resposta patológica completa em pacientes com câncer de mama HER2 positivo (Gianni et al, 2010). 
Tabela 1: Informações descritivas dos participantes da pesquisa $(n=29)$.

\begin{tabular}{|c|c|c|}
\hline Idade & Total & $\%$ \\
\hline Entre 31 e 40 anos & 11 & $38 \%$ \\
\hline Entre 41 e 50 anos & 9 & $31 \%$ \\
\hline Entre 51 e 60 anos & 5 & $17 \%$ \\
\hline Acima de 60 anos & 4 & $14 \%$ \\
\hline \multicolumn{3}{|l|}{ Estadiamento TNM } \\
\hline TNM I & 4 & $14 \%$ \\
\hline TNM II & 11 & $38 \%$ \\
\hline TNM III & 14 & $48 \%$ \\
\hline \multicolumn{3}{|l|}{ Tamanho do tumor Pré-Quimioterapia } \\
\hline Entre 10 e $30 \mathrm{~mm}$ & 15 & $51 \%$ \\
\hline Entre 31 e $50 \mathrm{~mm}$ & 5 & $17 \%$ \\
\hline Entre 51 e $70 \mathrm{~mm}$ & 1 & $4 \%$ \\
\hline Entre 71 e $90 \mathrm{~mm}$ & 1 & $4 \%$ \\
\hline Não informado & 7 & $24 \%$ \\
\hline \multicolumn{3}{|l|}{ Presença de receptores } \\
\hline Receptor de estrogênio (RE) & 23 & $79 \%$ \\
\hline Receptor de progesterona (RP) & 22 & $76 \%$ \\
\hline Receptor HER2 & 12 & $41 \%$ \\
\hline \multicolumn{3}{|l|}{ Presença de Ki-67 positivo (>14)? } \\
\hline Sim & 17 & $59 \%$ \\
\hline Não & 11 & $38 \%$ \\
\hline Não informado & 1 & $3 \%$ \\
\hline \multicolumn{3}{|l|}{ Subtipos moleculares } \\
\hline Luminal A & 10 & $35 \%$ \\
\hline Luminal B & 7 & $24 \%$ \\
\hline Triplo negativo & 3 & $10 \%$ \\
\hline HER2 & 9 & $31 \%$ \\
\hline \multicolumn{3}{|l|}{ Tipos Histológicos } \\
\hline Carcinoma ductal infiltrante (CDI) & 27 & $93 \%$ \\
\hline Carcinoma lobular invasivo (CLI) & 2 & $7 \%$ \\
\hline
\end{tabular}

Fonte: Autores (2021).

Uma diferença significativa foi observada nesta pesquisa levando em consideração a associação de receptores hormonais. Das 29 pacientes passíveis de análise, 79\% apresentavam receptores de estrogênio (ER) positivos (Tabela 1), dentre estas, $61 \%$ não obtiveram pCR em comparação com 39\% que alcançaram a pCR. Vários estudos têm demonstrado uma associação negativa entre a taxa de pCR e expressão de receptores hormonais (Von Minckwitz et al., 2005a; Von Minckwitz et al., 2005b; Gianni et al., 2005; Colleoni et al., 2000; Ring et al., 2004; Guarneri et al., 2006), contudo no presente trabalho não foi possível determinar a associação entre ER positivo com taxa de $\mathrm{pCR}(\mathrm{p}=0,33)$. Por exemplo no European Cooperative Trial in Operable breast cancer (ECTO), uma análise multivariada em que o ER foi considerado a única variável independente capaz de ser associada ao alcance da PCR (p <0,0001; OR 5,77). A discrepância da taxa de PCR entre estes pacientes que apresentavam tumores ER negativos e positivos foi bem alta neste estudo (42\% versus 12\%, respectivamente) (Gianni et al., 2005). Além deste, o estudo de Colleoni et al. (2000) também demonstrou que pacientes com tumores com HR (receptores para estrogênio e progesterona) negativos tiveram um alcance maior de PCR comparado aos que possuíam tumores com HR positivos (23\% vs. $7 \%$, respectivamente; $\mathrm{P}=0,04)$. 
Tabela 2: Comparação entre grupos de mulheres que obtiveram resposta patológica completa (pCR) no tratamento do câncer de mama $(n=29)$.

\begin{tabular}{|c|c|c|c|c|}
\hline Variável & $\operatorname{pCR}(n=13)$ & Sem pCR $(n=16)$ & $\begin{array}{l}\text { Razão de Chances } \\
\text { (IC) }\end{array}$ & Valor $\mathbf{p}$ \\
\hline Idade média & 44,5 & 48,8 & & 0,15 \\
\hline \multicolumn{5}{|l|}{ Estadiamento TNM } \\
\hline TNM I + II & 8 & 7 & 2,06 & \multirow{2}{*}{0,46} \\
\hline TNM III & 5 & 9 & $(0,37-11,86)$ & \\
\hline $\begin{array}{l}\text { Presença de receptor de } \\
\text { estrogênio }\end{array}$ & 9 & 14 & $\begin{array}{c}0,33 \\
(0,02-2,90)\end{array}$ & 0,33 \\
\hline $\begin{array}{l}\text { Presença de receptor de } \\
\text { progesterona }\end{array}$ & 9 & 13 & $\begin{array}{c}0,53 \\
(0,06-4,01)\end{array}$ & 0,66 \\
\hline Presença de HER2 & 10 & 2 & $\begin{array}{c}19,91 \\
(2,55-282,41)\end{array}$ & $<0,001$ \\
\hline $\mathrm{Ki}-67 \geq 14$ & 9 & 8 & $\begin{array}{c}2,19 \\
(0,39-14,11)\end{array}$ & 0,45 \\
\hline Ki-67 $<14$ & 3 & 8 & $\begin{array}{c}0,35 \\
(0,04-2,13)\end{array}$ & 0,25 \\
\hline Luminal A & 2 & 8 & $\begin{array}{c}0,35 \\
(0,03-2,79)\end{array}$ & 0,39 \\
\hline Luminal B & 3 & 4 & $\begin{array}{c}1,75 \\
(0,19-15,41)\end{array}$ & 0,65 \\
\hline HER Puro & 8 & 1 & $\begin{array}{c}20,98 \\
(2,04-1124,37)\end{array}$ & $<0,01$ \\
\hline Triplo negativo & 0 & 3 & $\begin{array}{c}0 \\
(0-2,89)\end{array}$ & 0,23 \\
\hline \multicolumn{5}{|l|}{ Tipo histológico } \\
\hline $\begin{array}{l}\text { Carcinoma ductal invasivo } \\
\text { (CDI) }\end{array}$ & 12 & 15 & \multirow{3}{*}{$\begin{array}{c}0,81 \\
(0,01-67,94)\end{array}$} & \multirow[b]{2}{*}{1} \\
\hline $\begin{array}{l}\text { Carcinoma lobular invasivo } \\
(\mathrm{CLI})\end{array}$ & 1 & 1 & & \\
\hline $\begin{array}{l}\text { Tamanho médio Pré- } \\
\text { Quimioterapia }(\mathrm{mm})\end{array}$ & 26,9 & 33,3 & & 0,49 \\
\hline
\end{tabular}

Fonte: Autores (2021).

Constata-se que $69 \%$ das pacientes que alcançaram pCR e que foram submetidas ao tratamento neoadjuvante possuíam o índice de proliferação celular, Ki-67, aumentado ( $\geq 14)$, contudo não foi possível afirmar que a expressão de tal fator possui associação positiva com pCR (p=0,35) (Tabela 2). Tal associação foi alcançada e estabelecida em outros estudos (Esserman et al., 2012; Tan et al., 2014). Em um trabalho realizado nos EUA em que, de 190 pacientes analisadas, 166 possuíam análise do Ki-67, a taxa de PCR foi significativamente maior nas pacientes que apresentavam o Ki-67 alto (34\% em comparação a $11 \%$ no grupo Ki-67 baixo/médio). Os valores de corte estabelecidos no trabalho citado foram classificados em índice de proliferação baixo, intermediário e alto para: menos de 10\%, de 10\% a 25\% e acima de 25\% (Esserman et al., 2012), porém, ainda assim é possível verificar que valores maiores de núcleos de células tumorais corados por Ki-67, indicando maior proliferação celular, possuem uma correlação positiva em se alcançar pCR.

Por fim, a idade média de diagnóstico das pacientes que tiveram pCR foi de 45 anos, sendo que a menor idade registrada foi de 33 anos, e maior de 64. Embora estudo realizado por Chou et al (2019) demonstrou que pacientes mais jovens têm maior chance de evolução para pCR, não foi possível associar neste estudo menor idade com maior prevalência de pCR $(\mathrm{p}=0,15)$ (Tabela 2). O perfil clínico do grupo se dá por: 14\% em estágio clínico I, 38\% estágio II e 48\% grau III (Tabela 1). Também não houve associação com TNM I e II com maior prevalência de evolução para pCR $(\mathrm{p}=0,46)$ 
Em relação ao tipo histológico, 93\% das pacientes que alcançaram resposta patológica completa tinham Carcinoma Ductal Invasor (CDI) e 7\% Carcinoma Lobular Invasor (CLI) (Tabela 1). Quanto aos subtipos moleculares das pacientes que evoluíram para pCR, 15\% das pacientes apresentaram subtipo Luminal A, 23\% o subtipo luminal B, 61\% eram subtipo HER-2 e nenhuma paciente apresentou o subtipo triplo negativo. Foi possível associar a presença do subtipo HER-2 com maior prevalência de $\mathrm{pCR}(\mathrm{p}<0,01$; OR 20,98) (Tabela 2).

Além disso, pacientes que apresentam receptores HER-2 podem se beneficiar de novas modalidades terapêuticas que utilizam anticorpos monoclonais, como o trastuzumab, associado a quimioterapia ou na modalidade de bloqueio duplo do receptor HER2 quando associado com outro anticorpo. Embora existam estudos afirmando benefícios na forma de ampliação da resposta patológica completa (Llombard-Cussac et al, 2017; Wang et al, 2020; Gianni et al, 2010), novos estudos multicêntricos são necessários para confirmar os resultados.

Por fim, a principal limitação deste estudo foi a pequena amostra que reduziu consideravelmente o poder do teste (1$\beta$ ), aumentando a ocorrência de erros do tipo II, quando não se rejeita a hipótese nula quando esta é falsa. Desta forma, não foi possível demonstrar neste trabalho associação com significância estatística em diversas associações demonstradas na literatura acadêmica devido a pequena amostra deste estudo. Dessa forma, futuros estudos podem utilizar amostras maiores para avaliar fatores associados com maiores chances de evolução para pCR em pacientes com neoplasia na mama

Mesmo com essas limitações, o objetivo de analisar as características clínico-patológicas de pacientes que alcançaram resposta patológica completa como resultado da quimioterapia neoadjuvante, na prática clínica de um centro de oncologia com pacientes "na vida real", fora de ambientes de estudos, foi alcançado. O propósito foi o de elucidação de fatores que possam contribuir para melhor desfecho clínico nessa modalidade de tratamento.

\section{Conclusão}

Foram associadas a presença de HER2 $(p<0,001)$ e o subtipo molecular HER2 puro $(p<0,01)$ com maior prevalência de evolução para pCR (Tabela 2). Fatores como presença de receptores hormonais de estrogênio ( $\mathrm{p}=0,33$ ), receptores hormonais de progesterona ( $\mathrm{p}=0,66), \mathrm{Ki}-67 \geq 14$ ( $\mathrm{p}=0,45)$ não foram associados neste estudo com $\mathrm{pCR}$, embora tenham dados na literatura associando negativamente a taxa de pCR com a expressão de receptores hormonais (Von Minckwitz et al., 2005a; Von Minckwitz et al., 2005b; Gianni et al., 2005; Colleoni et al., 2000; Ring et al., 2004; Guarneri et al., 2006) e associando positivamente a taxa de pCR com maiores níveis de Ki-67 (Esserman et al., 2012; Tan et al., 2014) e idade (Chou et al, 2019). Outros fatores como idade $(\mathrm{p}=0,15)$, estadiamento TNM I e II $(\mathrm{p}=0,46)$ também não apresentaram associação com desfecho pCR.

Conclui-se que o perfil das pacientes que obtêm pCR, considerando dados da literatura científica e deste estudo, são pacientes mais jovens que apresentam maiores níveis de Ki-67, ausência de receptores hormonais de estrogênio e progesterona e presença de receptores HER-2.

\section{Referências}

Andrade, D. A. P. de, Zucca-Matthes, G., Vieira, R. A. da C., Andrade, C. T. de A. E. de, Costa, A. M. da, Monteiro, A. J. de C., Dal Lago, L., \& Nunes, J. S. (2013). Quimioterapia neoadjuvante e resposta patológica: coorte retrospectiva. Einstein (São Paulo), 11(4), 446-450. https://doi.org/10.1590/s167945082013000400007

Asselain, B., Barlow, W., Bartlett, J., Bergh, J., Bergsten-Nordström, E., Bliss, J., Boccardo, F., Boddington, C., Bogaerts, J., Bonadonna, G., Bradley, R., Brain, E., Braybrooke, J., Broet, P., Bryant, J., Burrett, J., Cameron, D., Clarke, M., Coates, A., \& Zujewski, J. A. (2018). Long-term outcomes for neoadjuvant versus adjuvant chemotherapy in early breast cancer: meta-analysis of individual patient data from ten randomised trials. The Lancet Oncology, 19(1), 27-39. https://doi.org/10.1016/S1470-2045(17)30777-5

Campbell, J. I., Yau, C., Krass, P., Moore, D., Carey, L. A., Au, A., Chhieng, D., Giri, D., Livasy, C., Mies, C., Rabban, J., Sarode, V. R., Singh, B., Esserman, L., \& Chen, Y. Y. (2017). Comparison of residual cancer burden, American Joint Committee on Cancer staging and pathologic complete response 
in breast cancer after neoadjuvant chemotherapy: results from the I-SPY 1 TRIAL (CALGB 150007/150012; ACRIN 6657). Breast Cancer Research and Treatment, 165(1), 181-191. https://doi.org/10.1007/s10549-017-4303-8

Chou, H. H., Kuo, W. L., Yu, C. C., Tsai, H. P., Shen, S. C., Chu, C. H., Yu, M. C., Lo, Y. F., Dabora, M. A., Chang, H. K., Lin, Y. C., Ueng, S. H., \& Chen, S. C. (2019). Impact of age on pathological complete response and locoregional recurrence in locally advanced breast cancer after neoadjuvant chemotherapy. Biomedical Journal, 42(1), 66-74. https://doi.org/10.1016/j.bj.2018.10.007

Colleoni, M., Minchella, I., Mazzarol, G., Nole, F., Peruzzotti, G., Rocca, A., Viale, G., Orlando, L., Ferretti, G., Curigli ano, G., Veronesi, P., Intra, M., \& Goldhirsch, A. (2000). Original article Response to primary chemotherapy in breast cancer patients with tumors. Annals of Oncology, 11, 1057-1059. http://dx.doi.org/10.1023/a:1008334404825

Cortazar, P., \& Geyer, C. E. (2015). Pathological Complete Response in Neoadjuvant Treatment of Breast Cancer. Annals of Surgical Oncology, 22(5), 14411446. https://doi.org/10.1245/s10434-015-4404-8

Cortazar, P., Zhang, L., Untch, M., Mehta, K., Costantino, J. P., Wolmark, N., Bonnefoi, H., Cameron, D., Gianni, L., Valagussa, P., Swain, S. M., Prowell, T., Loibl, S., Wickerham, D. L., Bogaerts, J., Baselga, J., Perou, C., Blumenthal, G., Blohmer, J., ... Von Minckwitz, G. (2014). Pathological complete response and long-term clinical benefit in breast cancer: The CTNeoBC pooled analysis. The Lancet, 384(9938), 164-172. https://doi.org/10.1016/S0140$6736(13) 62422-8$

Esserman, L. J., Berry, D. A., DeMichele, A., Carey, L., Davis, S. E., Buxton, M., Hudis, C., Gray, J. W., Perou, C., Yau, C., Livasy, C., Krontiras, H., Montgomery, L., Tripathy, D., Lehman, C., Liu, M. C., Olopade, O. I., Rugo, H. S., Carpenter, J. T., \& Hylton, N. (2012). Pathologic complete response predicts recurrence-free survival more effectively by cancer subset: Results from the I-SPY 1 TRIAL - CALGB 150007/150012, ACRIN 6657. Journal of Clinical Oncology, 30(26), 3242-3249. https://doi.org/10.1200/JCO.2011.39.2779

Fayanju, O. M., Ren, Y., Thomas, S. M., Greenup, R. A., Plichta, J. K., Rosenberger, L. H., Tamirisa, N., Force, J., Boughey, J. C., Hyslop, T., \& Hwang, E. S. (2018). The clinical significance of breast-only and node-only pathologic complete response (PCR) after neoadjuvant chemotherapy (NACT): A review of 20,000 breast cancer patients in the National Cancer Data Base (NCDB). Annals of Surgery, 268(4), 591-601. https://doi.org/10.1097/SLA.0000000000002953

Gianni, L., Baselga, J., Eiermann, W., Porta, V. G., Semiglazov, V., Lluch, A., Zambetti, M., Sabadell, D., Raab, G., Cussac, A. L., Bozhok, A., MartinezAgulló, A., Greco, M., Byakhov, M., Lopez Lopez, J. J., Mansutti, M., Valagussa, P., \& Bonadonna, G. (2005). Feasibility and tolerability of sequential doxorubicin/paclitaxel followed by cyclophosphamide, methotrexate, and fluorouracil and its effects on tumor response as preoperative therapy. Clinical Cancer Research, 11(24), 8715-8721. https://doi.org/10.1158/1078-0432.CCR-05-0539

Gianni, L., Eiermann, W., Semiglazov, V., Manikhas, A., Lluch, A., Tjulandin, S., Zambetti, M., Vazquez, F., Byakhow, M., Lichinitser, M., Climent, M. A., Ciruelos, E., Ojeda, B., Mansutti, M., Bozhok, A., Baronio, R., Feyereislova, A., Barton, C., Valagussa, P., \& Baselga, J. (2010). Neoadjuvant chemotherapy with trastuzumab followed by adjuvant trastuzumab versus neoadjuvant chemotherapy alone, in patients with HER2-positive locally advanced breast cancer (the NOAH trial): a randomised controlled superiority trial with a parallel HER2-negative cohort. The Lancet, 375(9712), 377-384. https://doi.org/10.1016/S0140-6736(09)61964-4

Gralow, J. R., Burstein, H. J., Wood, W., Hortobagyi, G. N., Gianni, L., Von Minckwitz, G., Buzdar, A. U., Smith, I. E., Symmans, W. F., Singh, B., \& Winer, E. P. (2008). Preoperative therapy in invasive breast cancer: Pathologic assessment and systemic therapy issues in operable disease. Journal of Clinical Oncology, 26(5), 814-819. https://doi.org/10.1200/JCO.2007.15.3510

Guarneri, V., Broglio, K., Kau, S. W., Cristofanilli, M., Buzdar, A. U., Valero, V., Buchholz, T., Meric, F., Middleton, L., Hortobagyi, G. N., \& GonzalezAngulo, A. M. (2006). Prognostic value of pathologic complete response after primary chemotherapy in relation to hormone receptor status and other factors. Journal of Clinical Oncology, 24(7), 1037-1044. https://doi.org/10.1200/JCO.2005.02.6914

Huang, E. H., Tucker, S. L., Strom, E. A., McNeese, M. D., Kuerer, H. M., Buzdar, A. U., Valero, V., Perkins, G. H., Schechter, N. R., Hunt, K. K., Sahin, A. A., Hortobagyi, G. N., \& Buchholz, T. A. (2004). Postmastectomy radiation improves local-regional control and survival for selected patients with locally advanced breast cancer treated with neoadjuvant chemotherapy and mastectomy. Journal of Clinical Oncology, 22(23), 4639-4647. https://doi.org/10.1200/JCO.2004.11.129

Jones, R. L., Lakhani, S. R., Ring, A. E., Ashley, S., Walsh, G., \& Smith, I. E. (2006). Pathological complete response and residual DCIS following neoadjuvant chemotherapy for breast carcinoma. British Journal of Cancer, 94(3), 358-362. https://doi.org/10.1038/sj.bjc.6602950

Llombart-Cussac, A., Cortés, J., Paré, L., Galván, P., Bermejo, B., Martínez, N., Vidal, M., Pernas, S., López, R., Muñoz, M., Nuciforo, P., Morales, S., Oliveira, M., de la Peña, L., Peláez, A., \& Prat, A. (2017). HER2-enriched subtype as a predictor of pathological complete response following trastuzumab and lapatinib without chemotherapy in early-stage HER2-positive breast cancer (PAMELA): an open-label, single-group, multicentre, phase 2 trial. The Lancet Oncology, 18(4), 545-554. https://doi.org/10.1016/S1470-2045(17)30021-9

Mamtani, A., Barrio, A. V., King, T. A., Van Zee, K. J., Plitas, G., Pilewskie, M., El-Tamer, M., Gemignani, M. L., Heerdt, A. S., Sclafani, L. M., Sacchini, V., Cody, H. S., Patil, S., \& Morrow, M. (2016). How Often Does Neoadjuvant Chemotherapy Avoid Axillary Dissection in Patients With Histologically Confirmed Nodal Metastases? Results of a Prospective Study. Annals of Surgical Oncology, 23(11), 3467-3474. https://doi.org/10.1245/s10434-016-5246-8

McGuire, S. E., Gonzalez-Angulo, A. M., Huang, E. H., Tucker, S. L., Kau, S. W. C., Yu, T. K., Strom, E. A., Oh, J. L., Woodward, W. A., Tereffe, W., Hunt, K. K., Kuerer, H. M., Sahin, A. A., Hortobagyi, G. N., \& Buchholz, T. A. (2007). Postmastectomy Radiation Improves the Outcome of Patients With Locally Advanced Breast Cancer Who Achieve a Pathologic Complete Response to Neoadjuvant Chemotherapy. International Journal of Radiation Oncology Biology Physics, 68(4), 1004-1009. https://doi.org/10.1016/j.ijrobp.2007.01.023

Osório, C. A. B. T., Júnior, M. A. C., \& Soares, F. A. (2012). Avaliação de resposta patológica em câncer de mama após quimioterapia neoadjuvante: Padronização de protocolo adaptado. Jornal Brasileiro de Patologia e Medicina Laboratorial, 48(6), 447-453. https://doi.org/10.1590/S167624442012000600010 
Research, Society and Development, v. 10, n. 6, e18610615461, 2021

(CC BY 4.0) | ISSN 2525-3409 | DOI: http://dx.doi.org/10.33448/rsd-v10i6.15461

Rastogi, P., Anderson, S. J., Bear, H. D., Geyer, C. E., Kahlenberg, M. S., Robidoux, A., Margolese, R. G., Hoehn, J. L., Vogel, V. G., Dakhil, S. R., Tamkus, D., King, K. M., Pajon, E. R., Wright, M. J., Robert, J., Paik, S., Mamounas, E. P., \& Wolmark, N. (2008). Preoperative chemotherapy: Updates of national surgical adjuvant breast and bowel project protocols B-18 and B-27. Journal of Clinical Oncology, 26(5), 778-785. https://doi.org/10.1200/JCO.2007.15.0235

Ring, A. E., Smith, I. E., Ashley, S., Fulford, L. G., \& Lakhani, S. R. (2004). Oestrogen receptor status, pathological complete response and prognosis in patients receiving neoadjuvant chemotherapy for early breast cancer. British Journal of Cancer, 91(12), 2012-2017. https://doi.org/10.1038/sj.bjc.6602235

Tan, M. C., Al Mushawah, F., Gao, F., Aft, R. L., Gillanders, W. E., Eberlein, T. J., \& Margenthaler, J. A. (2009). Predictors of complete pathological response after neoadjuvant systemic therapy for breast cancer. American Journal of Surgery, 198(4), 520-525. https://doi.org/10.1016/j.amjsurg.2009.06.004

Tan, Q. X., Qin, Q. H., Yang, W. P., Mo, Q. G., \& Wei, C. Y. (2014). Prognostic value of Ki67 expression in HR-negative breast cancer before and after neoadjuvant chemotherapy. International Journal of Clinical and Experimental Pathology, 7(10), 6862-6870.

Von Minckwitz, G., Untch, M., Blohmer, J. U., Costa, S. D., Eidtmann, H., Fasching, P. A., Gerber, B., Eiermann, W., Hilfrich, J., Huober, J., Jackisch, C., Kaufmann, M., Konecny, G. E., Denkert, C., Nekljudova, V., Mehta, K., \& Loibl, S. (2012). Definition and impact of pathologic complete response on prognosis after neoadjuvant chemotherapy in various intrinsic breast cancer subtypes. Journal of Clinical Oncology, 30(15), 1796-1804. https://doi.org/10.1200/JCO.2011.38.8595

Von Minckwitz, G., Raab, G., Caputo, A., Schütte, M., Hilfrich, J., Blohmer, J. U., Gerber, B., Costa, S. D., Merkle, E., Eidtmann, H., Lampe, D., Jackisch, C., Du Bois, A., \& Kaufmann, M. (2005a). Doxorubicin with cyclophosphamide followed by docetaxel every 21 days compared with doxorubicin and docetaxel every 14 days as preoperative treatment in operable breast cancer: The GEPARDUO study of the German Breast Group. Journal of Clinical Oncology, 23(12), 2676-2685. https://doi.org/10.1200/JCO.2005.05.078

Von Minckwitz, G., Blohmer, J. U., Raab, G., Löhr, A., Gerber, B., Heinrich, G., Eidtmann, H., Kaufmann, M., Hilfrich, J., Jackisch, C., Zuna, I., \& Costa, S D. (2005b). In vivo chemosensitivity-adapted preoperative chemotherapy in patients with early-stage breast cancer: The GEPARTRIO pilot study. Annals of Oncology, 16(1), 56-63. https://doi.org/10.1093/annonc/mdi001

Wang, C., Chen, J., Xu, X., Hu, X., Kong, D., Liang, G., \& Wang, X. (2020). Dual HER2 Blockade in Neoadjuvant Treatment of HER2+ Breast Cancer: A Meta-Analysis and Review. Technology in Cancer Research \& Treatment, 19, 1-10. https://doi.org/10.1177/1533033820960721

Wolmark, N., Wang, J., Mamounas, E., Bryant, J., \& Fisher, B. (2001). Preoperative chemotherapy in patients with operable breast cancer: nine-year results from National Surgical Adjuvant Breast and Bowel Project B-18. Journal of the National Cancer Institute. Monographs, 15212(30), 96-102. https://doi.org/10.1093/oxfordjournals.jncimonographs.a003469 